\title{
Reflections
}

\section{Science, Objectivity and Ethics in Research Methodology}

\author{
Nasr Arif
}

Islam recognizes that Truth is infinite and that different methods are necessary to reach its different aspects. In other words, in the Islamic paradigm, each methodology has its appropriate domain which admits the possibility of certitude while allowing for openness. Clearly, this is the polar opposite of the relativist who claims that no method can reach Truth; he denies certitude and dogmatically insists that there is no such thing as Truth. However, the self-contradictory nature of the assertion proves it is false. ${ }^{1}$

From the Islamic point of view, no single methodology can make a claim on all knowledge contained in all fields and at all levels. This is reflected in the traditional formula inserted at the end of scholarly treatises wa'llahu a'lam "God knows best," for no scholar can claim to have come to the end of knowledge, thereby encompassing the infinite Truth in a self-contained system of thought.

The Islamic approach to knowledge refuses to accept partial truth as if it were the whole, and a single methodology as if it were the only methodology. Objectivity requires recognizing a partial truth for what it is, and not making monopolistic claims on knowledge with a single methodology. This recognition limits the abuse of power by those who would deny other valid methodologies and "ways of knowing."2

Recognizing the multiplicity of methods requires discernment as to their correct application in specific domains. This requires wisdom and a fully operational intelligence unobscured by passion. In other words, the intelligence or 'aql must be wholesome - the ethics and justice of the researcher being a necessary condition for discerning appropriate methodologies. Muslim scholars, therefore, emphasize the ethical training of the scientist to ensure the just selection of methodologies in each domain.

Nasr Arif is a visiting professor at the School of Islamic and Social Sciences and the Center for Muslim-Christian Understanding at Georgetown University. 
The western approach, on the other hand, adopts a single "scientific" methodology as the only way to knowledge, thereby claiming a monopoly on the truth, and accepting the partial truths this method yields. This approach is hardly objective, and opens the door for abuse of power. Indeed, the West focuses on the method rather than the scientist; it insists that its sole method is objective and the ethics of the scientist are irrelevant, rather than recognizing that multiple methods are possible and that the ethics of the scientist are crucial to their correct use. Moreover, because the West overemphasizes a single method many have been led to deny that any method can reach truth, thus opening the door to relativism and reinforcing the belief that, in the training of scientists ethics is irrelevant. However, recognizing the limitations of a single method and that it does not have a monopoly on knowledge should not lead to rejecting all methods of reaching truth. This is particularly true in the case of social sciences where the need for multiple methodologies is most obvious.

This paper consists of two parts. The first focuses on objectivity and is divided into three sections: (1) the objectivity of science, (2) the objectivity of scientists, and (3) methodological problems. The second part of the paper is concerned with research ethics in the Islamic paradigm and is also divided into three sections: (1) the level of researcher training, (2) the scientists' qualifications, and (3) the level of scholarly evaluation.

\section{Modes of Objectivity}

The problem of objectivity is one of the most widely debated issues in science. It is subject to a great deal of disagreement and contradiction among researchers and depends on their premises. The word "objectivity" is used to negate the validity of any idea or thesis outside the sphere of science. In this sense, it has been used as an authority resembling the medieval Church of Europe. The problem of objectivity arises from the assumption that there is a separation or clear duality between "fact" and "value."

In principle, this duality is based on the myth of ethical neutrality in a value-free social science discussed by G.E. Moore in his Principia Ethica in 1903. His argument was quite consistent with the positivist theses of his day, restricting science to what can be empirically proven.

Accordingly, only facts were considered to be capable of being known. Values, on the other hand, were reduced to an inferior status. This dichotomy between "fact" and "value" led to another epistemological dichotomy between "subjectivity" and "objectivity."3 Thus, science was limited to empirical phenomena that everyone could analyze and evaluate quantitatively without the subject's interference, thus generalizing or 
globalizing results which were assumed to be fully independent of time and place. ${ }^{4}$

Two modes of objectivity are distinguished. The first refers to objectivity as a specific characteristic of scientific methodology. As pointed out earlier, objectivity was conceived as the systematic, empirical study of various phenomena leading to truthful generalizations that could be empirically verified by repeating the experiment. The second mode refers to objectivity as a characteristic of the orientation and practices of scientists. It concerns behavior of researchers and practitioners known for their disinterest and exclusion of bias. ${ }^{5}$

Both modes of objectivity face great criticism from opponents of positivism. Their critiques point out that the argument for objectivity is a self-contradictory result of philosophical postulates, restricting science to the empirical without empirical proof. Most of the philosophical principles and postulates of the positivist school were neither tested in reality nor emerged from it. They were merely normative philosophical postulates that claimed to be the only criteria differentiating what is scientific from what is nonscientific. ${ }^{6}$

\section{The Objectivity of Science}

First, it should be noted that many philosophers and scientists reject the idea of separating "facts" from "values" or distinguishing between the subjective and the objective. They argue that human experience is a unified one that has multiple variations. For example, Peter Winch rejected the separation of the human experience into subjective and objective, "facts" and "values," or "real" and "nonreal" experience. He maintains that there is a well-established multiplicity and variance in human experiences. Thus, it is unacceptable to generalize the European experience and claim its domination over other human experiences. No human experience can judge the realism, rationality, and objectivity of others. ${ }^{7}$

Other thinkers and scientists point out that the debate about "facts" and "values" is illusory because it assumes they are separable - as if facts are totally separated from values. The truth is that most principal political concepts bear the two meanings at the same time. In other words, it has an aspect that relates to the empirical reality, and another that relates to values.

Each political concept has a portion relevant to fact and another relevant to values. For example, freedom, equality, democracy, legitimacy, participation, stability, growth, underdevelopment are political concepts that contain both fact and value meanings. Similarly, the statement that "someone had a successful surgical operation" refers to a fact, yet, represents a value judgment as well. ${ }^{8}$

On the other hand, some researchers and thinkers point out that distinguishing between fact and value is a sort of a value judgment itself that 
is based on a normative perspective or bias that defines fact and value. ${ }^{9}$ Moreover, the mere choice of the subject of study, the hypotheses that are tested, together with the usage of certain concepts (such as good or bad, accepted or rejected, what should be or what is preferable, ...etc.) also introduce bias. ${ }^{10}$

In addition, the definition of the essential concepts may have important implications: through the process of social interaction a dominant class may impose its own interpretation of reality over others while claiming objectivity for itself. In this sense, the choice of concepts and the resulting implications may reinforce value judgments and social biases. ${ }^{11}$

According to this argument, science is not practiced within a cultural or societal vacuum. It is not influenced only by its internal logic, but is an integrated part within this impure world in which we live. Thus, it is always subject to the economic and political powers that violate and abuse science for political, commercial, or military interests. ${ }^{12}$

According to a third argument involving the concept of objectivity, we do not regard reality the way it is. We only make up our vision of reality and our perception of the world in general according to its reflection in our subjective natures. In this sense, there is no purely objective world which we are bound to regard as representing reality. The world is not the sum total of existing things. It is the interaction between the human selves reflecting multiple meanings and imposing them over things. Husserl, therefore, maintained that there is no objective science regardless of how seriously we interpret each thing.

If these limitations on the objectivity of a single method in science are considered, we cannot separate the thinker from his thought and the scientist from his responsibility by appealing to a totalitarian methodology. More generally, we cannot separate man from the reality he studies with this approach because reality is very complex and the world's elements are shaped according to our perspectives and interpretations. The more we examine the elements of reality from different perspectives, the more aspects we can see. ${ }^{13}$

What we can realize or observe using a single method may be nothing but the net result of an interaction between our senses and the world that surrounds us. Therefore, the perception we gain is totally different from the actual reality. ${ }^{14}$ Peter Winch emphasizes that empirical observation in itself does not enjoy sufficient power to generate specific hypotheses in social sciences. In refuting the monopolistic claims of positivist methodology, the logical implications of Winch's position opens the door to relativism, for he maintains that abstract logic is not a direct gift from God, and is not a comprehensive objective truth that goes beyond the subjective self of the human being. He argues that logic emerged through the interactions and contradictions within a certain society. ${ }^{15}$ 
Moreover, he claims that societal reality can never be separated from ideology, religion, or culture. ${ }^{16}$

However, the solution to the limitations of a single methodology does not lie in relativism. Rather, the solution lies in the recognition of multiple methodologies, and the application of metaphysical principles to define the scope and domain of each. Indeed, metaphysics cannot be separated from science, for as Aristotle pointed out, metaphysics represents the science of scientific hypotheses. ${ }^{17}$

\section{The Objectivity of Scientists}

There may be no empirical proof that a researcher is objective. Since the mid-1970s, a plethora of writings espousing "radical science" has presented evidence for the non-neutral nature of scientists in various fields including medicine and technology. These works highlighted the process by which the politically dominating powers formulate a certain perspective for science and technology. ${ }^{18}$

A review of the self-criticism of many natural and social scientists reveals the great sorrow and regret they have for certain applications of their research in fields such as nuclear physics and molecular biology. Many social scientists who became involved in the military industrial complex were reproducing the bourgeois ideology. ${ }^{19}$

In addition, in this context it should be noted that science depends on government, institutional, and organizational funding, and that scientists interact with and are dominated by the interests of various economic, political, and military powers. These elements belie the romantic notion of science as "pure," going beyond the actual existing world and the daily life of scientists. ${ }^{20}$

Moreover, many scientists are guided by a search for beauty and symmetry in various equations, often leading them to correct results. Therefore, Cunningham's conclusion in the introduction of his book on objectivity and social sciences that it is possible to reach correct results and conclusions by means of nonobjective tools should be emphasized. It is also possible to reach the wrong results and conclusions using "objective" tools. Thus, there is no connection between the results of the research and the objectivity of tools or procedures. ${ }^{21}$

\section{Methodological Problems}

There are many problems associated with the attitude of researchers and practitioners in the field of social sciences, especially those who determine the orientation and content of the methodological steps of any research. Always relying on a single methodology does not exempt the research from the subjectivity of the researcher.

Many scholars point out that social phenomena are very different from natural or biological ones since the quantifiable parameters of the latter 
can be measured by means of physical instruments. They maintain that social phenomena represent a very complicated issue in which the subjective and objective aspects are intertwined, and that the methodology and its tools are conducted through the perceptions and senses of the researcher. Therefore, they insist on the importance of making the researcher aware of his value system. Moreover, some specialists insist on studying the link between the scientific analysis and the ideological interpretations of events in a way that makes this problem easier to understand and explain. Wiatr considered that this dimension of value is one of the most crucial ones in comparative research. He opposed the naive belief of the positivist school which claimed the existence of a value-free science. The transnational approach, for example, uses researchers from different backgrounds who represent different cultural environments with a wide diversity of value systems. Thus, they are expected to perceive, interpret, and understand various problems and phenomena in different ways.

In this sense, the discussions of the "Budapest Conference" on transnational comparative research were concluded by asserting the necessity of uncovering the value judgments of any research, declaring the principle bias of the researcher instead of suppressing that bias or claiming that it does not exist.

If the goal of transparency is achieved, modes of bias can be freely discussed so as to detect, measure, and specify them. This would point out the differences between these biases and their relative extent, in addition to the crucial impact of ideological diversity on research conclusions. ${ }^{22}$

On the other hand, societies do differ in their cultural pattern and behavioral values. Because of this, social scientists require training to analyze them properly. Indeed, they must learn where, how, and in what subjects they may raise their questions and conduct their interviews; for example, some regard the ability to speak fluently as a positive value while others regard silence as preferable. In addition, this training would point out the issues and problems that should never be discussed with strangers or even raised by a researcher to his interviewees. ${ }^{23}$

There are other problems raised concerning the mode of formation of research groups and the way they are administrated and funded. Scientific research generally requires a high budget to train and execute its research activities. Because research needs capital-rich institutions to provide its necessary funds the research group might lose its independence. The funding institutions, organizations, or countries are seeking certain interests that benefit their own goals, even if these goals are noble such as international peace. Any of these teleological orientations will deeply influence the fairness and neutrality of the research. This point must be stated and well-understood because research is often conducted to discredit a ruling regime, or to gain legitimacy for a ruling regime, or 
for some other political purpose. Moreover, there are other problems such as the leadership of the research group, the method of decision making, time allocation, reporting, using electronic devices, and the status of researchers (i.e., whether they are part-time or specialized full-time employees). ${ }^{24}$

Scholars of methodology point out that many researchers in the field of social sciences might be tied to certain values, biases, or cultural ethno-centrisms without realizing the mode of diversity, pluralism, or even contradiction that characterizes human cultures and societies. There may be many interpretations for the same phenomenon, some of which might be contradictory, depending on the society where it is found and the historical phase when it appears. For example, the analysis of a party member voting against his own party differs from the United States to Britain and other countries. In addition, scholars note that the value judgments or standards of the researcher together with his background, culture, and interests he represents or advocates influence his research. The way a researcher describes, investigates, interprets, and understands the phenomenon can be determined by these elements. Hence, there is no one way to answer certain questions such as When does a powerful ruler turn into a dictator? When is violent behavior a defense of freedom and when is it a criminal terrorist action? or When does a national independence movement become a revolutionary movement or a terrorist gang?

The answers to these questions are subject to value judgments that cannot easily be isolated or removed from scientific analysis, especially if the research involves more than one society or culture. And if the researcher himself belongs to one of societies or cultures being studied then it is assumed that his language and terminology contain bias and subjectivity. ${ }^{25}$

\section{Research Ethics in the Islamic Paradigm}

First, it should be emphasized that the Islamic paradigm refers to the epistemological structures, frameworks, methodologies, analytical tools, postulates, and grand assumptions formulated by the Islamic tradition, whether the person belonging and contributing to Islamic civilization was Muslim or Christian. Hence, the Islamic paradigm refers to a comprehensive worldview and a specific methodology for dealing with, understanding, and explaining the world, regardless of the religious belief of the one adopting this paradigm. As regards the epistemological nature and the methodological structure of the Islamic paradigm, a great deal of concern was devoted to the issue of the scientist's objectivity and the ethics of scientific investigation. These issues were discussed in the Islamic traditional literature under the title of ethics and manners of science required for the researcher, student, and teacher. 
On the other hand, the issue of the objectivity of science as it is raised in the Western paradigm is hardly found in the Islamic experience because of the specific perspective of the Islamic paradigm on science and knowledge, i.e., its nature, structure, and technical vocabulary. The Islamic paradigm is based on the fact that Truth is infinite. Truth cannot be measured, calculated, or expressed entirely. The Islamic tradition recognizes a multiplicity of methods in scientific research which can never exhaust the Truth, but which come as close as possible to gaining some of its "light." This allows for certainty at different levels of reality without limiting reality to a single level. In this sense, knowledge of the phenomenal world is indefinite, and science in the Islamic perspective is not the final word. Research on various phenomena in the universe and in existence is a continuous, renewing effort parallel to the existence of the human mind and the motion of the universe.

The Islamic perspective regards the science of phenomena to be in the process of renewal and transformation. Because God is infinite, natural, physical, and social phenomena are changing all the time. The human mind is also witnessing this continuous change in the world of becoming, and has a variety of methods by which to study this change, whether quantitatively or qualitatively. The multiplicity of methods and points of view allow for a great deal of pluralism and diversity in approach. Many factors influence this diversity such as education, culture, political socialization, human modes, and other specific differences. Because knowledge implies an interaction between the subject which knows and the object which is known, any change in one element of the equation will induce a change in the result.

Different research tools represent a link between the human mind and the issue being investigated. The use of tools can expand in certain methodologies, illustrating the capabilities of the thinking human being and reflecting the characteristics of the issue of the research. ${ }^{26}$

Because the Islamic paradigm recognizes the existence of the Supreme Being that has ultimate knowledge, Muslim scientists end their scientific conclusions with the phrase "Allah (God) knows best." In other words, reality is not limited to any given level of human understanding, and that Absolute Truth is surely deeper than any man can reach. The differences among the Muslim schools of jurisprudence (fiqh) and Muslim doctrines of faith were justified and accepted in the light of this understanding of the diversity of perspectives on the mountain of Truth, and human capacities to ascend it in understanding. ${ }^{27}$

It is quite natural to observe a change in the provisions of Islamic fiqh with the change of time and place, or the change in the surrounding circumstances influencing the way the faqih (interpreter of fiqh) perceives the problem he deals with. A faqih can change his ideas and judgments 
at various stages of his life, whenever he changes his place of residence or the society he lives in. ${ }^{28}$

The change of ideas and interpretations is viewed as a justified result of the change of the elements of the scientific process despite the continuity and stability of the absolute epistemological point of reference. Ibn Khaldun illustrates these ideas in the following quote:

The human mind is incapable of investigating all the details about beings, the causes of their existence, and the general details of the whole universe. The universe is limited to the perception of the one investigating it. The actual truth is always different from that perception and much beyond it. Couldn't you see that the deaf restricts his perception of this existence into only four senses, putting aside everything related to hearing. The same goes for the blind or others . If this was understood, it would suggest another mode of perception quite different from ours because our human perception is limited, narrow, and superficial. It is created by Almighty Allah who is the creator of all beings. What we perceive is limited or even unknown for real for us while the whole existence and the whole universe is much wider than that perception of ours. Almighty Allah is the supreme power who encompasses knowledge and the universe. ${ }^{29}$

The former presentation shows that the issue of the objectivity of science itself has been a concern for the researcher who follows the Islamic paradigm because of the emphasis on Truth and the multiple methodologies to reach it. The main focus was to emphasize the objectivity of scientists and the ethics of scientific research in order to purify the researcher's mind to discern appropriate methodologies, and defend their just application.

This orientation of the Muslim researcher recognizes that there is no right higher than the right of truth. It emphasizes seeking fairness and justice, being morally motivated, requiring accurate documentation, relating quotes and ideas to their authors, rational verification, thorough investigation, full commitment to reality, straightness and honesty in presenting conclusions, and complete fairness to opponents.

These values were at the heart of many studies, and were known in the traditional Islamic literature as "the ethics of students," "the ethics of scientists," or "the ethics of research, debate, and argument." Many research fields were enriched with these studies covering a variety of interests and involving numerous Islamic texts. ${ }^{30}$

The elements representing the interest of Muslim scientists in the issue of the ethics of scientific investigation were numerous. Indeed, ethics were considered necessary for the education and socialization of a productive scientist. They were regarded as elementary qualifications and 
determinants of the good scientist worthy of consideration and appreciation.

Ethics was also considered the standard for evaluating the scientific results of a scientist. It was said to be the foundation of credibility. All scientists and students followed the Islamic ethical system, which included justice, fairness, detecting truthful aspects of the matter, paying great attention to the evidence and other ways of verification, and orienting scientific activity toward God. These values required avoiding the influence of power and wealth (or the truth's subordination to them), the influence of the ruler or the political regime, flattery, hypocrisy, false argument, the passion for supremacy or glory, fanaticism, getting blindly biased to a certain methodology or ideology. The following analysis will shed some light on these dimensions of ethics in Islamic scientific research.

\section{On the Level of Researcher Training}

In the Islamic experience the quest for knowledge is not limited to a certain age or a certain phase in a student's life. Every human being from birth until death should seek knowledge. He might have a quest for knowledge without producing any scientific research. The quest for science and knowledge is a continuous process that should never be limited to a certain age group or phase of life. It should last throughout the human being's life.

Al-Shawkany, for example, focuses on the importance of making the student himself aware of the necessity of being totally fair and just in his quest for knowledge, as he should never be biased to a certain scientific doctrine or scientist. Fanaticism also should be left aside for the sake of treating all people equally. He points out that the reason for bias or fanaticism, which may induce a violation of the standards of fairness and justice, may be one of the following: (1) a person is brought up in a society that is strictly bound to a doctrine perceived to be the only ultimate truth (making its members accuse others outside their society of being wrong, unjust, illusioned, or misled) or his judgments are influenced by his social environment or mode of socialization; ${ }^{31}$ (2) a person seeks glory, prestige, wealth, and authority resulting in his submission to the whims of kings and rulers, siding with their points of view, or developing interpretations which are contradictory to fairness and justice, ${ }^{32}$ and (3) a person is irrational, uncontrolled, or bad mannered when working with members of a scientific group. Controlling ego-criticism can be a crucial element in this situation because some scientists wish to avoid revealing their mistakes for fear of losing their distinguished societal status. ${ }^{33}$ 


\section{On the Level of Scientists' Qualifications}

Many traditional Islamic works focused on the main qualities a scientist should have to make him worthy of joining the profession and enjoying its honor. These qualifications include the motivation to follow God's orders rather than any other worldly interests (whether in the form of money, wealth, fame, or reputation). A scientist should have a high standard of ethics and manners far removed from faulty ego-centrism or arrogance. $^{34}$

\section{On the Level of Scholarly Evaluation}

The ethics of the scientist has always been considered as an elementary consideration when evaluating the scientific output of any Muslim scientist, regardless of whether he originally formulated the scientific thesis, reinterpreted it, or conducted an experiment for it. A complete set of Islamic branches of knowledge was established for this particular purpose such as al-jarh wa al-ta'dill, the system of determining the veracity of narrators in the study of hadiths. ${ }^{35}$

The acceptance or rejection of a hadith narrator is based on certain standards. Thus, to accept someone as a transmiter of a hadith from the Prophet Muhammad, he must be well-known for being an upright, just, and religious person who has always been above suspicion, accusations of lying, or guilty of any nonacceptable deeds. There are many general and specific scientific, social, and moral qualifications required for such a person to be accepted. With all these dimensions, there has been a comprehensive set of ethics and external conditions to be followed for any Islamic scientific research. One of the most important is referential quoting, or relating ideas and statements to their original author, as well as following standardized methodological procedures such as naming the sources, references, and other documentation. ${ }^{36}$

Such ethics and manners were propagated and strengthened in the Islamic paradigm. Muslim scientists and researchers were committed to these ethics in all Muslim sciences including the linguistic, juridical, or even natural sciences.

Al-Hassan ibn Al-Haitham, a well-known Muslim scientist, described his scientific approach in the introduction of his book Al-Manazer. $\mathrm{He}$ stated:

We start our research by the induction of everything existing, investigating the conditions of the seen things, and distinguishing the characteristics of all elements. In this way we should pick up all that belongs to the sense of vision, what's stable and unchangeable, and the things that are apparently uninfluenced by the senses. Then, the research and measurements will gradually move to a higher stage as we criticize our premises and put conditions on our conclusions and induction. Throughout this process, we are submitting our- 
selves to justice, not following our desires. In everything we are investigating or criticizing, we are seeking the truth, not merely supporting our opinion. ${ }^{37}$

These are some determinants of the ethics of scientific research in the Islamic paradigm which are quite different from the dominant western approach. By emphasizing the ethics and objectivity of the scientist in the application of multiple methodologies, there might be a degree of convergence from an exchange of views and ideas between the two paradigms. This could encourage progress and mutual benefit on the bases of verification and criticism of postulates, foundations, and hypotheses. This can come only after an accurate examination of the major issues in the definition of science, the definition of methodology, and the overall worldview of both Islamic and western paradigms.

\section{Notes}

1. See Frithjof Schuon, Logic and Transcendence (Middlesex: Perennial Books, 1984). The opening paragraph reads, "Relativism sets out to reduce every element of absoluteness to a relativity, while making a quite illogical exception in favor of this reduction itself. In effect, relativism consists in declaring it to be true that there is no such thing as truth, or in declaring it to be absolutely true that nothing but the relatively true exists; one might just as well say that language does not exist, or write that there is no such things as writing. In short, every idea is reduced to a relativity of some sort, whether psychological, historical, or social; but the assertion nullifies itself by the fact that it too presents itself as a psychological, historical, or social relativity. The assertion nullifies itself if it is true, and by nullifying itself logically proves thereby that it is false; its initial absurdity lies in the implicit claim to be unique in escaping, as if by enchantment, from a relativity that is declared alone to be possible."

2. On the different ways of knowing and their application in Islamic science, see Seyyed Hossein Nasr, Science and Civilization in Islam (New York: Barnes and Noble Publications, 1992), Rene Guenon, Crisis of the Modern World (Paris: Luzac, 1945), especially chapter 4 on "Sacred and Profane Science," and Osman Bakar, Tawhid and Science (Kuala Lumpur: Secretariat for Islamic Philosophy and Science, 1991).

3. Peter R. Senn, Social Sciences and Its Methods (Boston: Holbrook Press, 1971), 55 .

David Ray Griffin, "The Reenchantment of Science," the introduction to The Reenchantment of Science: Postmodern Proposals, ed. David Ray Griffin (New York: State University of New York Press, 1988), 5.

William P. Brandon, '“Fact' and 'Value' in the Thought of Peter Winch: Linguistic Analysis," Political Theory 10, no. 2 (May 1982): 217-218.

4. Alanc Isaak, Scope and Methods of Political Science: An Introduction to the Methodology of Political Inquiry (III: The Dorsey press, 1969 ), 24.

5. Helen E. Longino, Science as Social Knowledge: Values and Objectivity in Scientific Inquiry (New Jersey: Princeton University Press, 1990), 66.

6. Edmund Mokrzycki, "What to Take into Account when Comparing? The Problem of Context," in Niessen, Manfred, and Pescher, Jules eds. International Comparative Research: Problems and Theory Methodology and Organization in Eastern and Western Europe (Oxford: Pergamon Press, 1982), 97.

7. Brandon, '"Fact' and 'Value' in the Thought of Peter Winch: Linguistic Analysis," 219-220.

8. Felix E. Oppenlim, “"Facts' and 'Values' Are They Separable?” Political Theory

1, no. 1 (February 1973): 54-63.

9. Senn, Social Sciences and Its Methods, 55-56.

10. Ibid., 37. 
11. Robert R. Alford, and Roger Friedland, Powers Theory: Capitalism, the State, and Democracy (Cambridge: Cambridge University Press, 1985), 26-27.

12. Steward Richard, Philosophy and Sociology of Science (Oxford: Basil, Blackwell, 1987), 171.

13. David Halbrook, Education and Philosophical Anthropology (London: Associated University Press, 1987), 150-151.

14. Harold Brown, Observation and Objectivity (New York: Oxford University Press, 1987), v.

15. Brandon, '"Fact' and 'Value' in the Thought of Peter Winch: Linguistic Analysis," 227-228.

16. Longino, Science as Social Knowledge: Values and Objectivity in Scientific Inquiry, 187-194.

17. George J. Graham, Methodological Foundation for Political Analysis (Mass.: Xerox College Publishing, 1971), 236.

18. Les Levidow, ed., Science as Politics (London: Free Association Books, 1986), 3.

19. Richards, op. cit. ., pp. $128-129$, and William Outhwaite, Concept formation in social sciences, ( London : Routhedge and Kegan Paul, 1983) p1

20. Richards, Philosophy and Sociology of Science, 127-128.

21. Frank Cunningham, Objectivity in Social Science (Toronto: University of Toronto Press, 1973), 3.

22. Ibid., 366.

23. William H. Form, "Field Problem in Comparative Research: the Politics of Distrust," in Comparative Social Research: Methodological Problems and Strategies, Armer, Micheal, and Allen Grinshaw, eds. (New York: Avuley Interscience Publication, 1973), 93.

24. Jan Berting, Felix Geyer, and Ray Jurkovich, eds, Problems in International Comparative Research in the Social Sciences (Oxford, New York: Pargamon Press, 1979), 12.

25. Rod Hague and Martin Harrop, Comparative Government and Politics: an International (London: Macmillan Education, 1987), 19-20.

26. Nasr Arif, Contemporary Theories of Development: A Critical Comparative Study in the Light of the Islamic Civilizational Perspective (Cairo: Arab Reader Publication House, 1993), 9 (in Arabic).

27. For the reasons of difference among Muslim faqihs see for example: Mohamed Said Ramadan Al Bouty, Lectures on Comparative Islamic Fiqh Showing the Reasons of Difference among Muslim Faqihs (Damascus: Al-Fiqr House, 1981).

28. On the change of Islamic provisions following the change in time and place see for example: Ibn Al Qaim Al Gawzia, Aalam Al-Mouaqin, vol. 3, (Cairo, undated), 15-70 (in Arabic); and Sayed Ibrahim Darwish, "The Change of Fatwa with the Change of Condition in Islamic Shari'ah," a Ph.D. dissertation (Faculty of Shari'ah and Law, AlAzhar University, 1986).

29. Abdel Rahman Ibn Khaldoun, Al-Muqaddimah, 3rd edition, edited by Aly Abdel Wahid Wafy (Cairo: Al-Nahda Printing and Publication House, 1981), 1071 (in Arabic).

30. See, for example: Mohamed Ibn Aly Al Shawkany, Talab al-'Tlm wa Tadaqat alMutalmin: Adab al-Talab wa Muntaha al-Adab (Beirut: Scientific Books Publication House, 1982) (in Arabic); Al-Imam Al-Nawawi, Adab al-Mu'alim wa al-Mutalim wa alMufti wa al-Mustafti wa Fadl Talib al-'Ilm (Tanta, Egypt: Al-Sahaba Publication House, no date); Abo Bakr Alagry, Akhlaq al-'Ulama', 2nd edition, (Casablanca, Morocco: AlThaqafa House, 1984) (in Arabic); Abu Hilal Al-Askary, Al-Haath 'ala Talab al-'Ilm wa al-Ijtihad fi Gamah (Beirut, Lebanon: The Islamic Bureau, 1986); Ibn Abdel Barr, Gamih Bayan al-'Ilm wa Fadluh wa ma Yanbaghi fi Riwaytih wa Hamlh, (Cairo: Dar al-Fateh, undated); Abu Abdal Allah Mohamed Bin Said Raslan : Adab Talib Al Elm, Cairo , Islamic sciences house, 1st edition, 1988 (in Arabic ); Al-Alusy, Canon Ahkam Al Elm Wa Al Alim Wa Motaalim, manuscript no. 22662 (Cairo University).

31. Al-Shawkany, Talab al-'Ilm wa Sadaqat al-Mutalmin: Adab al-Talab wa Muntaha al-Adab, 10-11.

32. Ibid., 23.

33. Ibid., 260.

34. Al-Imam Al-Nawawi Adab al-Mu'alim wa al-Mutalim wa al-Mufti wa al-Mustafti wa Fadl Talib al-'Ilm, 29-31; see also Abdal Ra'uf Yusif Abdal Qadr, Ethics of Students and Teachers as Stated by Abu Bakr Aagri (Beirut: Dar al-Geel, 1991), 66-69. 
35. See, for example: Faruq Hamada, The Islamic Methodology of al-Jarh wa alTa'adil: a Methodological Study of al-Hadith Science Knowledge (Al-Rabat, Morocco: Publication House, 1989) (in Arabic).

36. Nasser Muhammad Abdal Rahman Ramadan, Scientific Communication in Islamic Heritage from the Early Islamic History till the End of the Abbassids, (Cairo: Ghareib Printing and Publication House, 1994), 189-246 (in Arabic).

37. Al-Hassan ibn al-Haitham, Al-Manazer (Kuwait, 1983), 62 (in Arabic). 